This item was submitted to Loughborough's Research Repository by the author.

Items in Figshare are protected by copyright, with all rights reserved, unless otherwise indicated.

\title{
A study of perturbations in linear and circular polarized antennas in close proximity to the human body and dielectric liquid filled rectangular and a cylindrical phantom at $1.8 \mathrm{GHz}$
}

\section{PLEASE CITE THE PUBLISHED VERSION}

http://www.lapconf.co.uk/lapc2010.php

\section{PUBLISHER}

Loughborough University (@ IEEE)

\section{VERSION}

VoR (Version of Record)

\section{LICENCE}

CC BY-NC-ND 4.0

\section{REPOSITORY RECORD}

Khattak, Muhammad I., R.M. Edwards, Oluwaseun A. Ojerinde, C.J. Panagamuwa, and M. Gul. 2019. "A Study of Perturbations in Linear and Circular Polarized Antennas in Close Proximity to the Human Body and Dielectric Liquid Filled Rectangular and a Cylindrical Phantom at 1.8 Ghz". figshare. https://hdl.handle.net/2134/8098. 
This item was submitted to Loughborough's Institutional Repository (https://dspace.lboro.ac.uk/) by the author and is made available under the following Creative Commons Licence conditions.



For the full text of this licence, please go to: http://creativecommons.org/licenses/by-nc-nd/2.5/ 


\title{
A Study of Perturbations in Linear and Circular Polarized Antennas in close proximity to the Human Body and Dielectric Liquid Filled Rectangular and a Cylindrical Phantom at $1.8 \mathrm{GHz}$
}

\author{
M. I. Khattak ${ }^{(1)}$, R. M. Edwards ${ }^{(1)}$, O.A. Ojerinde ${ }^{(1)}$, C. J. Panagamuwa ${ }^{(1)}$ and M. Gul ${ }^{(2)}$ \\ (1) Electronic and Electrical Engineering \\ The University of Loughborough \\ Loughborough, LE11 3TU, UK \\ (2) Electronic and Electrical Engineering \\ NWFP UET Peshawar, Pakistan \\ M.I.Khattak@lboro.ac.uk \\ R.M.Edwards@lboro.ac.uk
}

\begin{abstract}
In the design and synthesis of wearable antennas isolation distance from the body is a critical parameter. This paper deals with the comparison of perturbations caused to the matching of simple linear and circular polarized patch antennas due to the close proximity of a human torso and rectangular box and cylindrical phantoms filled with muscle simulating liquid at 1.8GHz. The isolated variable is return loss, $S_{11}(\mathrm{~dB})$. Results show that at these frequencies a cylindrical phantom resembles the body more closely than a rectangular phantom.
\end{abstract}

\section{INTRODUCTION}

The incorporation of technology on and into the body is a growing trend in the field of mobile communications $[1,2]$. Substantial growth in the use of mobile phones and and communications enabled personal data assistants (PDAs) has also generated interest in the interaction of radiofrequency radiation with the body $[5,6]$. Since humans are made of tissue that is generally lossy the performance of any antenna operating close to humans will change as a function of frequency and proximity. In essence the closer an antenna is used to the skin the greater the proportion of field existing in tissue and therefore the greater the loss. This concludes to an increase in the rate of change with proximity to antenna parameters such as efficiency and pattern. At popular mobile communications frequencies between 0.9 to $2.5 \mathrm{GHz}$ the range over which an antenna begins to significantly suffer from proximity effects begins at approximately $40 \mathrm{~mm}$ from the body and ends with the antenna shorting out on the skin. Recollect that human tissue is conductive. Antennas therefore are best designed close to humans; however this may not be practical. Thus, phantoms with properties close to the human tissue are used in the range of frequency to be tested to simulate the human body in the design process. Many researchers have worked on the development of tissue-like phantoms for high and low water content human tissues at different frequencies. Early work exists in [9] and more recently, the authors of $[10,11]$ and [12] have been involved in the fabrication of phantoms for this purpose.

In wearable antennas, specific absorption rate (SAR) is important since it provides a measure of the interaction of fields with tissue and a high proportion of the energy produced by a wearable antenna may be absorbed by the body. Information on SAR levels associated with mobile phones and phantoms used for mobile phone testing can be found in [13$15]$.

It is clear though that although phantoms offer a reasonable alternative to on-body measurement, and in particular are important for standardisation they do not accurately reproduce antenna conditions in close proximity to skin $[16,17]$.

This paper presents a comparison between two of the most common phantom types in use (rectangular and cylindrical) and humans for the impedance perturbations of to two generic antenna types, namely probe fed patch antennas with linear and circular polarisation.

\section{Description of EXPERIMENT ANTENNAS, PHANTOM, VOLUNTEERS AND EQUIPMENT}

\section{A. Antenna and Spacer Design}

The antennas selected were microstrip patch antennas built on $1.6 \mathrm{~mm}$ thick fire resistant four (FR4) board. The designs of antennas used can be found in [18] and were modelled using the EM simulator Microstripes. Spacers were then used (4 off), to position the antenna ground plane above the back of our volunteer. Both these antennas along with the spacer are shown in figure 1 . The square patch antenna exhibits linear polarisation and the circular antenna exhibits auricular polarisation. 


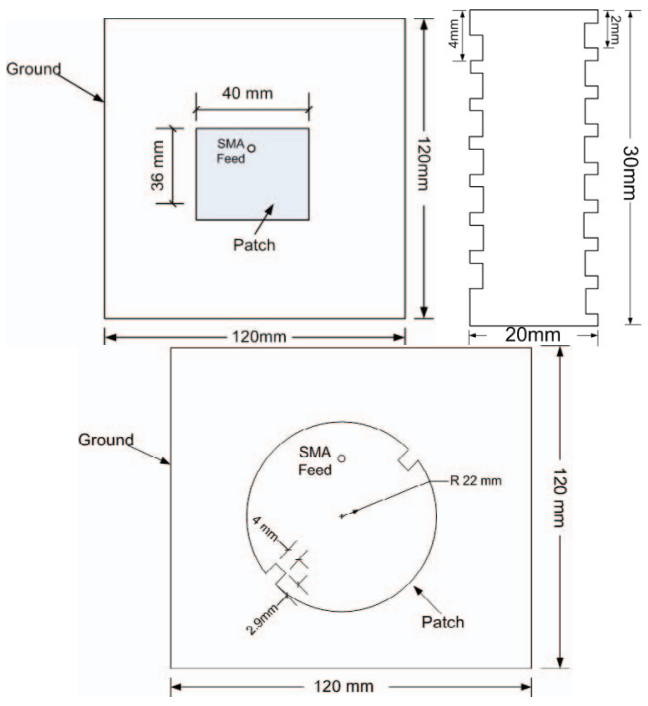

Figure 1: A line drawing of a linearly and circularly polarised patch antenna and an experimental spacer (Not to Scale).

Care was taken to ensure accurate calibration and minimise cable disturbance. Ferrite beads were used to choke off currents on the outer of the coaxial cable due to impedance mismatch at the feed. The measurement instrument was an Anritsu Portable Network Analyser MS2026A, which operated on batteries.

\section{B. Torso Phantoms with a Tissue Simulating Liquid}

In common with the standard test equipment for the standardisation of SAR measurements the rectangular and cylindrical phantoms were constructed as hollow shells from $2 \mathrm{~mm}$ thick glass fibre. The dimensions of the rectangular phantom were approximately $400 \mathrm{~mm}$ long, $320 \mathrm{~mm}$ wide and $210 \mathrm{~mm}$ high shown in figure 2 . The dimensions of the cylindrical phantom were taken from salty lite [19], approximately $305 \mathrm{~mm}$ and $400 \mathrm{~mm}$ high. This is also shown in figure 2. These dimensions were chosen to be closely representative of the volume of the torso of a male. Note that the use of $2 \mathrm{~mm}$ thick glass fibre phantoms in microwave measurements is now accepted practice [20]. The dielectric properties of the phantom and the muscle simulating liquid are shown in table 1 . For the volumes and part of the body chosen these values were obtained empirically. A recipe for the filling substance is given in [21]. Both phantoms were designed in such a way as to minimise air pockets on filling. However, slow filling and settling are advised to avoid air pockets.

TABLE 1: DIELECTRIC PROPERTIES OF MUSCLE SIMULATING LIQUID AND FR4 BOARD.

\begin{tabular}{|c|c|c|}
\hline & $\varepsilon_{r}$ & $\sigma(S / m)$ \\
\hline $\begin{array}{c}\text { Muscle Simulating } \\
\text { Liquid }\end{array}$ & 55.16 & 1.46 \\
\hline FR4 Board & 4.5 & 0 \\
\hline $\begin{array}{c}\text { PVC } \\
\text { (Spacer Material) }\end{array}$ & 4.0 & $10 \mathrm{e}(-6)$ \\
\hline
\end{tabular}

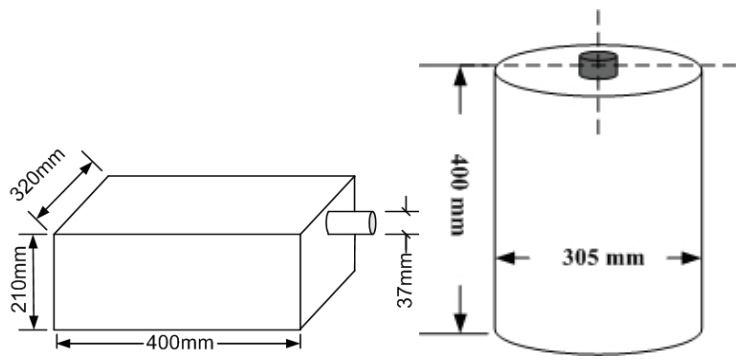

Figure 2: A line drawing of Torso Simulating Phantoms (Not to Scale).

\section{Experimental Method}

Previous work at Loughborough University had suggested that most garments have dielectric constants real of between 1 and 2.5 and are low loss. An exception is neoprene with a dielectric constant of 6 but this is still rare in clothing. Therefore we consider is reasonable to neglect clothing by making the assumption that the two major contributors to changes in antenna parameters when closed up to the body are the reflection at the air phantom/body interface and the loss in the tissue simulating liquid and the skin, muscle and blood of the torso.

After calibration the antenna return loss was measured at intervals of approximately $2 \mathrm{~mm}$ over the range 2 to $50 \mathrm{~mm}$. An on surface measurement was not taken since the conductivity of skin at $1.8 \mathrm{GHz}(1.2 \mathrm{~S} / \mathrm{m})$, effectively shorts out the antenna and prevents conducting surfaces pooling charge in the intended way. At $2 \mathrm{~mm}$ intervals the $S_{11}$ was recorded for phantom and human back. The abstracted drawings of Fig. 3 show the experiment in progress. Since the effects we are measuring are predominantly only sensitive in the very near field we considered it reasonable to take our measurements in a laboratory. However, as a check a second setup was designed in an anechoic chamber as shown in the Fig. 4. In this setup reflections were further attenuated by properly placed sections of absorber.

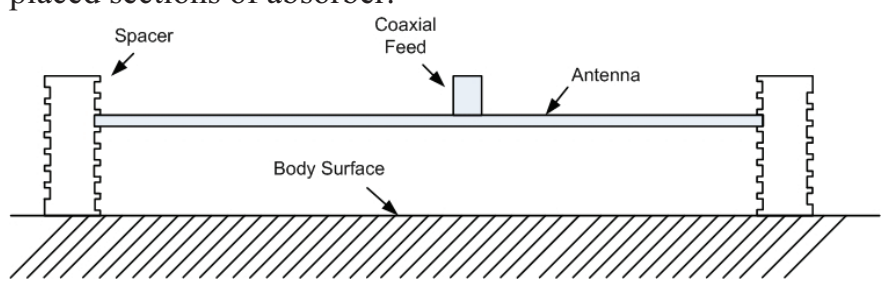

Figure 3: Placement of Antenna on the surface of Human Body. 




Figure 4: Placement of Antenna on the surface of Rectangular and Cylindrical Phantoms.

\section{RESULTS}

Figure 5 and Figure 6 shows the return loss versus distance from the surface of the volunteer's body and dielectric filled rectangular and cylindrical phantoms for linearly and circularly polarised antennas at $1.8 \mathrm{GHz}$. It can be seen that in the presence of the phantom the match is generally better closer to the rectangular phantom when compared to the cylindrical phantom and the body. The rates of change of the responses are roughly the same. Note that in general circularly polarised antennas exhibit lower Q than linear antennas and therefore the difference in rate of change of return loss is as expected. For both circularly and linearly polarised antennas the cylindrical phantom yielded results closer to those provided by human measurements.



Figure 5: Comparison of $\mathrm{S}_{11}(\mathrm{~dB})$ Measurements for Dielectric Liquid filled Phantom and Back of a Human Body for Linearly Polarised Antenna at $1.8 \mathrm{GHz}$



Figure 6: Comparison of $\mathrm{S}_{11}(\mathrm{~dB})$ Measurements for Dielectric Liquid filled Phantom and Back of a Human Body for Circularly Polarised Antenna at $1.8 \mathrm{GHz}$

\section{CONCLUSIONS}

This study was an extension to the previous work $[16,17]$ at Loughborough University to find out the effect of curvature of the human body simulating phantoms. Generally it was observed in these experiments that the body and the phantoms also detune the patch to a lower operating frequency of resonance and they both produce a broad-banding effect on the resonant curve. No correction has been made for this. Specifically by looking at Figure 5 and Figure 6 it was noticed that the cylindrical phantom gave better results. We reason that the presence of perpendicular edges on the rectangular phantom is the most likely cause for the difference in the two sets of measurements. However we can reasonably draw the following general conclusions:-

The phantoms change the match of the antenna in a similar way to a human torso. But it is advisable to use cylindrical phantom rather then rectangular one due to their resemblance with human torso shape. While the isolation distance should be increased when considering insulating layers of clothing for on body antennas if using a rectangular phantom for tuning. Similarly considering the linear and circular polarization of the antenna, results suggest that the best match for circularly polarized antennas occurs at double the distance as that of linearly polarised antenna.

\section{REFERENCES}

[1] J. W. Hines, "Medical and surgical applications of space biosensor technology," Acta Astronaut., vol. 38, pp. 261-267, 1996.

[2] S. Park and S. Jayaraman, "Enhancing the quality of life through wearable technology," IEEE Engineering in Medicine and Biology Magazine, vol. 22, pp. 41-48, 2003.

[3] M. Scheffler, E. Hirt, "Wearable devices for emerging healthcare applications", Proceedings of 26th annual International Conference of the IEEE EMBS, San Francisco, CA, USA, September 1-5, 2004.

[4] Fabrice Axisa, Pierre Michael Schmitt, Claudine Gehin, Georges Delhomme, Eric McAdams, and André Dittmar, "Flexible Technologies and Smart Clothing for Citizen Medicine, Home Healthcare, and Disease 
Prevention", IEEE Transactions on Information Technology in Biomedicine, Vol. 9, NO. 3, September 2005

[5] R. W. Y. Habash, Electromagnetic Fields and Radiation: Human Bioeffects and Safety. CRC, 2001,

[6] D. Poljak, A. Sarolic and V. Roje, "Human interaction with the electromagnetic field radiated from a cellular base station antennas," in EMC EUROPE 2002 International Symposium on Electromagnetic Compatibility,2002,

[7] Steve Mann, 'Humanistic Intelligence: 'WearComp' as a new framework and application for intelligent signal processing", Proceedings of the IEEE, Vol. 86, No. 11, November, 1998.

[8] S. Mann, "Wearable Wireless Webcam," personal WWW page, http://wearcam.org (http://n1nlf-1.media.mit.edu), 1994.

[9] A. Guy, "Analyses of electromagnetic fields induced in biological tissues by thermographic studies on equivalent phantom models," IEEE Trans.Microwave Theory Tech., vol. 19, pp. 205-214, 1968.

[10] A. Surowiec, P. Shrivastava, M. Astrahan and Z. Petrovich, "Utilization of a multilayer polyacrylamide phantom for evaluation of hyperthermia applicators," International Journal of Hyperthermia, vol. 8, pp. 795-807, 1992.

[11] C. McCann, J. Kumaradas, M. Gertner, S. Davidson, A. Dolan and M. Sherar, "Feasibility of salvage interstitial microwave thermal therapy for prostate carcinoma following failed brachytherapy: studies in a tissue equivalent phantom," Phys. Med. Biol., vol. 48, pp. 1041-1052, 2003.

[12] S. Davidson and M. Sherar, "Measurement of the thermal conductivity of polyacrylamide tissue-equivalent material," International Journal of Hyperthermia, vol. 19, pp. 551-562, 2003.

[13] C. Panagamuwa, W. Whittow, R. Edwards and J. Vardaxoglou, "Experimental verification of a modified Specific Anthropomorphic Mannequin (SAM) head used for SAR measurements," 2007.

[14] Whittow, W.G., Panagamuwa, C.J., Edwards, R.M. and McEvoy, P., "Investigating the Effect of Adding a Seam Along the Nose of the SAM Phantom to Allow Excitation from the Front," March 2006, Pp 1-9, Reports for EPSRC Grant no EP/C517490/1.

[15] W. Whittow, C. Panagamuwa, R. Edwards, J. Vardaxoglou and P. McEvoy, "A study of head worn jewellery, mobile phone RF energy and the effect of differing issue types on rates of absorption," 2006.

[16] M. I. Khattak, R. Edwards, J. Ma, C. Panagamuwa and A. Ullah, "A Study of Perturbations in Linear and Circular Polarized Antennas in close proximity to the Human Body and a Dielectric Liquid Filled Phantom at 1.8 GHz", European Conference on Antennas and Propagation, Barcelona, Spain, April 2010.

[17] M. I. Khattak; R. M. Edwards; J. Ma, "A Study of Perturbations due to Antennas in close proximity with the Human Body and Body Simulating Liquid Filled Phantoms at 1.8GHz", Loughborough Antennas \& Propagation Conference, $16^{\text {th }}$ and $17^{\text {th }}$ November, 2009.

[18] C. A. Balanis, "Antenna theory analysis and design," John Wily \& Sons Inc, 1997.

[19] Chen, C.; Babij, T.M.; "FD-TD analysis of scattering of electromagnetic fields close to phantom humans," Antennas and Propagation Society International Symposium, 1996. AP-S. Digest, vol.3, no., pp.16741677 vol.3, 21-26 Jul 1996.

[20] Y. Koyanagi, H. Kawai, K. Ogawa and K. Ito, "Consideration of the local SAR and radiation characteristics of a helical antenna using a cylindroid whole body phantom at $150 \mathrm{MHz}, "$ Electronics and Communications in Japan (Part I: Communications), vol. 87, 2004.

[21] Schmid \& partner engineering AG, DASY4 manual V4.1, march 2003. 